\title{
Varied DNA Polymerase-Substrate Interactions in the Nucleotide Binding Pocket
}

\author{
Michael Strerath, Daniel Summerer, and \\ Andreas Marx*[a]
}

\section{KEYWORDS:}

DNA polymerases - DNA recognition DNA replication nucleotide analogues - nucleotides

Faithful transfer of genetic information from one generation to its offspring is crucial for the survival of any living species. Genomic integrity relies greatly upon the ability of DNA polymerases to efficiently catalyze selective DNA synthesis in a template-directed manner. ${ }^{[1]}$ Despite enormous efforts in structural and functional studies, the complex mechanisms by which DNA polymerases ensure selective DNA synthesis are not fully understood. ${ }^{[2,3]}$ Recently, we introduced a functional strategy to monitor enzyme interactions that act on the sugar moiety of an incoming triphosphate within the nucleotide binding pocket of the Klenow fragment (Kf) of Escherischia coli DNA polymerase I (exo- mutant). ${ }^{[4]}$ We found that the nucleotide insertion selectivity of $\mathrm{Kf}^{-}$is increased approximately hundredfold when modified sugars $\mathbf{1 b}, \mathbf{c}$ (Scheme 1) are employed. This result strongly suggests the involvement of steric constraints, which act on the 2'-deoxyribose of an incoming nucleoside triphosphate in $\mathrm{Kf}^{-}$selectivity processes.

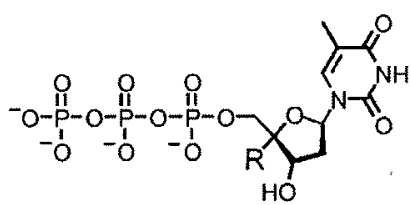

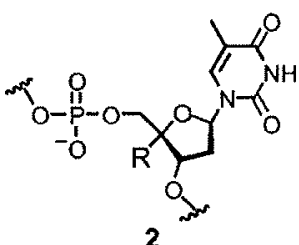

$$
\mathrm{R}=\mathbf{a}: \mathrm{H} ; \mathbf{b}: \mathrm{CH}_{3} ; \mathbf{c}: \mathrm{CH}_{2} \mathrm{CH}_{3} ; \mathbf{d}: \mathrm{CH}\left(\mathrm{CH}_{3}\right)_{2}
$$

Scheme 1. Thymidine analogues used as steric probes in functional DNA polymerase studies.

Further, new valuable insights into selective $\mathrm{Kf}^{-}$interactions with the sugar backbone in the minor groove were obtained through site-specific incorporation of thymidines $\mathbf{2 a - d}$ into primer template substrates. ${ }^{[5]}$ Herein, we investigate the interplay of $\mathrm{Kf}^{-}$with the $2^{\prime}$-deoxyribose moiety of the coding nucleotide by using steric probes $2 \mathbf{a}-\mathbf{d}$ in functional enzyme investigations. This is a particularly intriguing topic since

[a] Dr. A. Marx, Dipl.-Chem. M. Strerath, Dipl-Chem. D. Summerer Kekulé-institut für Organische Chemie und Biochemie Universität Bonn

Gerhard-Domagk-Strasse 1, 53121 Bonn (Germany)

Fax: $(+49)$ 228-73-5388

E-mail:a.marx@uni-bonn.de 
structural investigations strongly suggest the occurrence of large conformational changes within several DNA polymerases from an 'open' to a 'closed' conformation prior to phosphodiester bond formation. These conformational changes are triggered by 2 '-deoxyribonucleotide- $5^{\prime}$-triphosphate (dNTP) binding. ${ }^{[2 a-c, 3 d]}$ Editing of nascent nucleotide base pair geometry during these transitions is believed to be a crucial determinant of DNA polymerase selectivity. In analogy to our previous findings, one might assume that DNA polymerases tighten their grip on the substrate through enzyme-sugar interactions with the template nucleotide and thus increase enzyme selectivity.

In order to monitor DNA polymerase interactions with the sugar moiety of the coding nucleotide, we applied synthetic DNA substrates with $4^{\prime}$-alkylated nucleotide residues $2 \mathbf{b}-\mathbf{d}$ at specific sites (Scheme 1). ${ }^{[5]} \mathbf{2 a - d}$ serve as substrates in comparative gel-based primer extension assays, which were designed in such a way that the thymidine residue $2 \mathbf{a}-\mathbf{d}$ in the template strand is located adjacent to the $3^{\prime}$-primer end (Scheme 2).

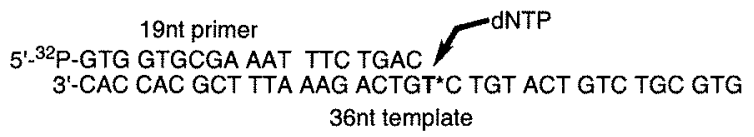

Scheme 2. DNA primer template substrates used in these studies. $T^{*}=\mathbf{2} a-d$; $d N T P=2^{\prime}$-deoxyribonucleotide-5'-triphosphate $; n t=$ nucleotide.

We first investigated $\mathrm{Kf}^{-}$-catalyzed canonical base pair formation opposite unmodified and modified thymidine residues. Figure 1 shows the pattern of insertion when varied concentrations of dATP are employed. Nucleotide insertion is exhibited

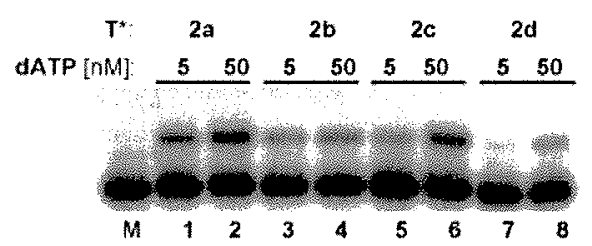

Figure 1. dATP insertion opposite $2 a-d$ catalyzed by KF-. DNA sequences are depicted in Scheme 2. For further details see the Experimental Section.

opposite modified thymidine moieties even at low dATP concentrations. Quantification of the insertion reactions that resulted when previously described single-nucleotide insertion assays were conducted under steady-state and single-completed-hit conditions ${ }^{[6]}$ revealed that nucleotide insertion by Kfopposite 4 -methylated thymidine template $\mathbf{2} \mathbf{b}$ occurred with a high efficiency (maximum reaction rate/Michaelis constant; $V_{\text {max }} / K_{M}$ ) comparable to insertion opposite unmodified thymidine 2 a (Table 1). Bulkier ethyl and ipropyl groups cause less efficient insertion opposite the modified residues. However, the differences between $\mathrm{Kf}^{-}$insertion abilities for various $4^{\prime}$-groups are less pronounced than those observed in experiments that employed substrate modifications mounted at the sugar residues of nucleoside triphosphates $1 \mathbf{b}-\mathbf{d} \cdot{ }^{[4]}$
Table 1. Stendy-state analyses for dATP insertion opposite template thyml dine analogues. to

\begin{tabular}{|llll|}
$\begin{array}{l}\text { Template } \\
\text { nucleotide }\end{array}$ & $K_{M}[\mu \mathrm{M}]$ & $\begin{array}{l}V_{\max } \\
{\left[\mathrm{min}^{-1} \times 10^{-3}\right]}\end{array}$ & $\begin{array}{l}\text { Efficiency } \\
{\left[\mathrm{M}^{-1} \mathrm{~min}^{-1} \times 10^{3}\right]}\end{array}$ \\
\hline 2 a & $0.0049 \pm 0.0009$ & $43 \pm 4$ & 8800 \\
2b & $0.0019 \pm 0.0003$ & $16 \pm 1$ & 8400 \\
2 c & $0.020 \pm 0.005$ & $45 \pm 1$ & 2300 \\
2d & $0.022 \pm 0.008$ & $19 \pm 3$ & 860 \\
\hline
\end{tabular}

[a] The data presented are averages of duplicate or triplicate experiments. [b] Efficiency $=V_{\max } / K_{M}$.

Next, we investigated the effect of the sugar modifications on $\mathrm{Kf}^{-}$selectivity when noncanonical dNTPs were applied as substrates. ${ }^{[7]}$ Since $\mathbf{2} \mathbf{b}$ has only minor effects on nucleotide insertion efficiency, it should be ideally suited to monitor the relevant differential interactions that act on the template nucleotide present in insertion and misinsertion events. Misinsertion studies of dGTP, dCTP, or TTP opposite $\mathbf{2 a}$ or $\mathbf{2 b}$ revealed negligible effects of the 4 -modification on $\mathrm{Kf}^{-}$catalyzed nucleotide misinsertion (Figure 2, Table 2) ${ }^{[8]}$ These findings are in marked contrast to our previous results obtained with $4^{\prime}$-modified triphosphates $1 \mathbf{b}$-d, in which we observed a one hundredfold increase in selectivity caused by the $4^{\prime}$-alkylation..$^{[4]}$ Thus, comparison of data obtained in this study with data from our recent study indicates that different enzyme-substrate interactions act on the sugar moieties of triphosphate and template nucleotide residues, respectively.

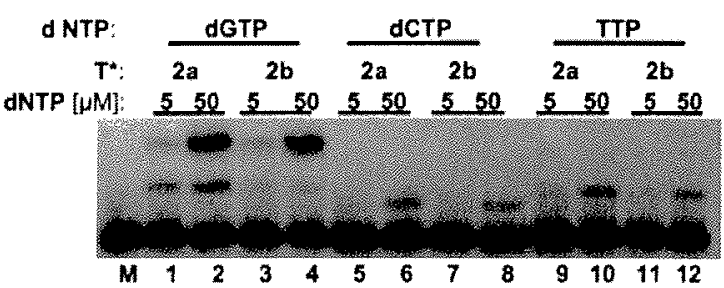

Figure 2. dNTP misinsertion opposite $2 a, b$ catalyzed by Kf-. DNA sequences are depicted in Scheme 2. For further details see the Experimental Section.

\begin{tabular}{|c|c|c|c|}
\hline Template nucleotide & $\kappa_{M}\left[\mu_{M}\right]$ & $\begin{array}{l}V_{\max } \\
{\left[\min ^{-1} \times 10^{-3}\right]}\end{array}$ & $\begin{array}{l}\text { Efficiency }{ }^{|b|} \\
{\left[\mathrm{M}^{-1} \min ^{-1} \times 10^{3}\right]}\end{array}$ \\
\hline \multicolumn{4}{|l|}{ dGTP misinsertion: } \\
\hline $2 a$ & $1.81 \pm 0.08$ & $30 \pm 2$ & 17 \\
\hline $2 b$ & $3.6 \pm 0.4$ & $56 \pm 1$ & 16 \\
\hline \multicolumn{4}{|l|}{ dCTP misinsertion: } \\
\hline $2 a$ & $57.5 \pm 5.8$ & $61 \pm 12$ & 1.1 \\
\hline $2 b$ & $25.9 \pm 1.7$ & $33 \pm 5$ & 1.3 \\
\hline \multicolumn{4}{|l|}{ TTP misinsertion: } \\
\hline $2 a$ & $38.4 \pm 3.4$ & $33 \pm 2$ & 0.9 \\
\hline $2 b$ & $30.9 \pm 0.5$ & $24 \pm 2$ & 0.8 \\
\hline
\end{tabular}

[a] The data presented are averages of duplicate or triplicate experiments. [b] Efficiency $=V_{\max } / K_{\mathrm{M}}$. 
Crystal structures of DNA polymerases bound to their DNA and nucleotide substrates are very useful for the correlation of functional data with enzyme structure. ${ }^{[2]}$ No such data is available for Kf. Nevertheless, corresponding structures from closely related Family A polymerases indicate the occurrence of large conformational changes after dNTP binding that are believed to be crucial for correct enzyme function. ${ }^{[2 a-c, 3]}$ However, the lack of a significant effect of $4^{\prime}$-methylated probe $\mathbf{2} \mathbf{b}$ on $\mathrm{Kf}^{-}$fidelity indicates that enzyme - sugar interactions that act on the template nucleotide sugar moiety might play a minor role in these selectivity mechanisms in the context of the sequence investigated.

Combined with our previous findings, ${ }^{[4]}$ the functional investigations presented herein suggest that enzyme-sugar interactions relevant for selectivity processes occur primarily with the sugar moiety of the incoming nucleoside triphosphate. ${ }^{[4]}$ These observations can be rationalized by a model for $\mathrm{Kf}^{-}$in which additional steric strain caused by supplementary small chemical modifications to the sugar at the triphosphate cause reduced flexibility primarily at the nucleotide binding site of the active site. The additional steric strain at this site might decrease tolerance for formation of geometrically altered nascent nucleotide pairs and thus increase overall $\mathrm{Kf}^{-}$fidelity. In future, comparative investigations of several DNA polymerases from different polymerase families might elucidate differences among these enzymes and provide further new insights into the origins of various DNA polymerase properties and functions, such as fidelity.

\section{Experimental Section}

Single nucleotide insertion and steady-state kinetics assays were conducted as described previously. ${ }^{[6]}$ In brief, two equivalents of template were annealed with $5^{t}-{ }^{32} \mathrm{P}$ labeled primer in the reaction buffer. The mixture was heated to $95^{\circ} \mathrm{C}$ for $2 \mathrm{~min}$ and subsequently allowed to cool to room temperature over $1 \mathrm{~h}$. After annealing, the appropriate amount of DNA polymerase was added and the solution was incubated at $0^{\circ} \mathrm{C}$ for $10 \mathrm{~min}$. Reactions were initiated by addition of the DNA/enzyme mixture $(10 \mu \mathrm{L})$ to an equal amount of dNTP solution in the reaction buffer and the mixtures were incubated at $37^{\circ} \mathrm{C}$. Kf- (New England Biolabs) reactions were performed in tris(hydroxymethyl)aminomethane (Tris) $\mathrm{HCl}(50 \mathrm{~mm} ; \mathrm{pH} 7.5), \mathrm{MgCl}_{2}$ (10 $\mathrm{mM})$, and DTT (1 mM). Assays included primer ( $50 \mathrm{~nm}$ ) and enzyme $(2 \mathrm{~nm})$. After incubation for the indicated time the reactions were quenched by addition of $60 \mu \mathrm{L}$ of gel loading buffer ( $80 \%$ formamide, ethylenediaminetetraacetate (EDTA; $20 \mathrm{~mm})$ ) and subsequently heated to $95^{\circ} \mathrm{C}$ for $10 \mathrm{~min}$. Reactions were analyzed by $14 \%$ PAGE on a gel that contained urea $(8 \mathrm{M})$, transferred to filter paper, dried under vacuum, and visualized by autoradiography.
Steady-state kinetic data were obtained from single nucleotide insertion assays, as described above. Concentrations of nucleotides, enzyme concentration, and reaction time were adjusted for different reactions in order to allow $20 \%$ or less primer extension, which ensured single-completed-hit conditions, according to published procedures. ${ }^{[6]}$ The reaction mixtures were fractionated by $14 \%$ denaturing PAGE and the data were quantified by phosphorimager analysis. Relative velocity $v$ was calculated from the amount of extended product $\left(l_{\text {ext }}\right)$ and remaining primer $\left(I_{\text {prim }}\right)$ as $v=l_{\text {ext }} / l_{\text {prim }} t$, where $t$ represents the reaction time. The apparent $K_{M}$ and $V_{\max }$ values were obtained from Hanes-Woolf plots as already described. ${ }^{[6]}$

We gratefully acknowledge financial support by the Deutsche Forschungsgemeinschaft and thank proressor Dr. M. Famulok for his continuing support

[1] A. Kornberg, T. A. Baker, DNA Replication, 2nd ed., W. H. Freeman and Company, New York, 1991.

[2] Recent reviews and commentaries: a) P. H. Patel, L. A. Loeb, Nat. Struct. Biol 2001, 8,656-659; b) P. H. Patel, M. Suzuki, E. Adman, A. Shinkai, L. A. Loeb, J. Mol. Biol. 2001, 308, 823-837; c) T. A. Kunkel, K. Bebenek, Annu, Rev. Biochem. 2000, 69, 497-529; d) E. T. Kool, J.C. Morales, K. M. Guckian Angew. Chem. 2000, 112, 1046-1068; Angew. Chem. Int. Ed. 2000, 39, 991 1009; e) T. A. Kunkel, S. H. Wilson, Nat. Struct. Biol, 1998, 5, 95-99; f) U. Diederichsen, Angew. Chem. 1998, 110, 1745-1747; Angew. Chem. Int. Ed. 1998, 37, 1655-1657; g) M. F. Goodman, Proc. Natl. Acad. Sci. USA 1997, 94 $10493-10495$.

[3] For selected DNA polymerase structures, see: a) H. Ling, F. Boudsocq, R. Woodgate, W. Yang, Cell 2001, 107, 91 - 102; b) M. C. Franklin, J. Wang, T. A Steitz, Cell 2001, 98, 413-416; c) S. Doublié, S. Tabor, A. M. Long, C. C. Richardson, T. Ellenberger, Nature 1998, 391, 251 - 258; d) Y. Li, S. Korolev, G. Waksman, EMBO J. 1998, 17, 7514-7525; e) J.R. Kiefer, C. Mao, J.C Braman, L. S. Beese, Nature 1998, 391, 304-307; f) H. F. Huang, R. Chopra, G. L. Verdine, S.C. Harrison, Science 1998, 282, 1669-1675; g) H. Pelletier, M. R. Sawaya, A. Kumar, S. H. Wilson, J. Kraut, Science 1994, 264, 1891 1903.

[4] D. Summerer, A. Marx, Angew. Chem. 2001, 113, 3806-3808; Angew. Chem. Int. Ed. 2001, 40, 3693-3695.

[5] D. Summerer, A. Marx, J. Am. Chem. Soc. 2002, 124, 910-911.

[6] a) D. K. Fygenson, M. F. Goodman, J. Biol. Chem. 1997, 272, 27931-27935; b) S. Creighton, L. B. Bloom, M. F. Goodman, Methods Enzymol. 1995, 262 $232-256$; c) M. F. Goodman, S. Creighton, L. B. Bloom, J. Petruska, Crit. Rev. Biochem. Mol. Biol. 1993, 28, 83-126; d) M. S. Boosalis, J. Petruska, M.F. Goodman, J. Biol. Chem. 1987, 262, 14689-14696.

[7] M. T. Hess, U. Schwitter, M. Petretta, B. Giese, H. Naegeli, Biochemistry 1997 $36,2332-2337$.

[8] For misinsertion experiments, relatively high dNTP concentrations have to be applied to detect nucleotide incorporation (Ref. [6b]). Higher dNTP concentrations cause nucleobase-dependent extension of DNA products as a result of misinsertion caused by mismatched extension. This provokes the generation of longer reaction products than expected through single nucleotide insertion alone (see Figure 2, lanes 1-4). 